\title{
Zmiany składu chemicznego i izotopowego (inwersja) metanu, etanu i propanu na przykładzie gazów z formacji łupkowych Barnett (basen Fort Worth) oraz Fayetteville (basen Arkoma)
}

\begin{abstract}
W złożach gazu z formacji łupkowych w USA o najwyższej produktywności zazwyczaj występuje inwersja składu izotopowego węgla w metanie, etanie i propanie. Efekt roll-over polega na zmianie normalnego trendu izotopowego $\left(\delta^{13} \mathrm{C}-\mathrm{C}_{1}<\delta^{13} \mathrm{C}-\mathrm{C}_{2}<\delta^{13} \mathrm{C}-\mathrm{C}_{3}\right)$ na odwrócony $\left(\delta^{13} \mathrm{C}-\mathrm{C}_{1}>\delta^{13} \mathrm{C}-\mathrm{C}_{2}>\delta^{13} \mathrm{C}-\mathrm{C}_{3}\right)$. Przyczyny takiej inwersji nie zostały dokładnie określone; najczęstszym wytłumaczeniem jest występowanie wtórnego krakingu ropy naftowej w skale macierzystej typu łupkowego. Zumberge wraz ze współpracownikami oznaczyli skład molekularny oraz izotopowy ponad 200 próbek gazów z formacji Barnett (basen Fort Worth) oraz Fayetteville (basen Arkoma). Dojrzałość termiczna tych basenów została określona na - odpowiednio - od około $1 \%$ do $2 \%$ oraz od około $2 \%$ do 3\% w skali refleksyjności witrynitu. Wyniki analiz składu gazu z formacji Barnett i Fayetteville zostały wykorzystane w tej pracy do określenia różnic w interpretacji, jakie napotyka się, stosując wzory i wykresy opracowane dla gazów konwencjonalnych do scharakteryzowania gazów niekonwencjonalnych.
\end{abstract}

Słowa kluczowe: shale gas, gaz z formacji łupkowych, skład chemiczny, skład izotopowy, $\delta^{13} \mathrm{C}$, gaz ziemny.

\section{Methane, ethane and propane chemical and isotopic composition changes (inversion) in natural gases from Barnett and Fayetteville shale plays}

\begin{abstract}
Inversion of the isotopic composition of carbon in methane, ethane and propane is common in the highest productivity shale formations in the United States. Roll-over effect is the reversion of normal isotopic trend from $\delta^{13} \mathrm{C}-\mathrm{C}_{1}<\delta^{13} \mathrm{C}-\mathrm{C}_{2}<\delta^{13} \mathrm{C}-\mathrm{C}_{3}$ to $\delta^{13} \mathrm{C}-\mathrm{C}_{1}>\delta^{13} \mathrm{C}-\mathrm{C}_{2}>\delta^{13} \mathrm{C}-\mathrm{C}_{3}$. The reasons for this inversion have not been clarified, but the most common explanation is the presence of secondary cracking of crude oil in shale source rock. Zumberge and colleagues determined the molecular and isotopic composition of more than 200 samples of gas from the Barnett formation (Fort Worth basin) and Fayetteville formation (Arkoma basin). Thermal maturity of these basins was determined, respectively, from about 1 to $2 \%$, and from about 2 to $3 \%$ vitrinite reflectance equivalent [9, 10]. The results of these analyzes were used to determine the differences in gas interpretation with formulas and diagrams developed for the conventional gases when used for unconventional gases.
\end{abstract}

Key words: shale gas, chemical composition, isotopic composition, $\delta^{13} \mathrm{C}$, natural gas.

\section{Wstęp}

Inwersja składu izotopowego (efekt roll-over) węgla $\mathrm{w}$ metanie, etanie i propanie polega na zmianie normalnego trendu $\left(\delta^{13} \mathrm{C}-\mathrm{C}_{1}<\delta^{13} \mathrm{C}-\mathrm{C}_{2}<\delta^{13} \mathrm{C}-\mathrm{C}_{3}\right)$ na odwrócony $\left(\delta^{13} \mathrm{C}-\mathrm{C}_{1}>\delta^{13} \mathrm{C}-\mathrm{C}_{2}>\delta^{13} \mathrm{C}-\mathrm{C}_{3}\right)$. Zmiana ta może być związana z: mieszaniem się gazów ze źródeł o różnych dojrzałościach termicznych, dodatkiem gazu biogenicznego, frakcjonowaniem izotopowym związanym z migracją, wtórnym krakingiem lub reakcjami Fischera-Tropscha [3]. Spośród teorii wyjaśniających przyczynę inwersji składu izotopowego najpowszechniejsza jest ta związana z wtórnym krakingiem ropy naftowej. 
Zumberge wraz ze współpracownikami oznaczyli skład molekularny oraz izotopowy ponad 200 próbek gazów z formacji Barnett (basen Fort Worth) oraz Fayetteville (basen Arkoma) [13]. Dojrzałość termiczna tych basenów została określona na - odpowiednio - od około $1 \%$ do $2 \%$ oraz od około $2 \%$ do $3 \%$ w skali refleksyjności witrynitu $[9,10]$. Podob- ne poziomy dojrzałości wykazują polskie formacje łupkowe [7]. Wyniki analiz składu gazu z formacji Barnett i Fayetteville zostały wykorzystane w tej pracy do określenia różnic w interpretacji, jakie napotyka się, stosując wzory i wykresy opracowane dla gazów konwencjonalnych do scharakteryzowania gazów niekonwencjonalnych.

\section{Skład chemiczny i izotopowy a dojrzałość termiczna}

W artykule Isotopic reversal rollover in shale gases produced from the Mississippian Barnett and Fayetteville formations autorzy przytaczają wyniki analiz składu chemicznego i izotopowego 129 próbek gazów z formacji Barnett i 100 próbek gazów z formacji Fayetteville [13]. Wartości minimalne, maksymalne, mediany i średnie arytmetyczne wyników analiz składu izotopowego $\left(\delta^{13} \mathrm{C}-\mathrm{C}_{1}, \delta^{13} \mathrm{C}-\mathrm{C}_{2}, \delta^{13} \mathrm{C}-\mathrm{C}_{3}\right.$ i $\delta \mathrm{D}-\mathrm{C}_{1}$ ) oraz wartości wskaźników wyliczonych na podstawie składu chemicznego $\left(\mathrm{C}_{1} /\left(\mathrm{C}_{2}+\mathrm{C}_{3}\right), \mathrm{C}_{2} / \mathrm{C}_{3}, \mathrm{i}-\mathrm{C}_{4} / \mathrm{n}-\mathrm{C}_{4}\right.$ $\mathrm{i}$ i- $\mathrm{C}_{5} / \mathrm{n}-\mathrm{C}_{5}$ ) dla formacji Barnett i Fayetteville przedstawiono w tablicach 1 i 2 .

Skład izotopowy węgla w metanie, etanie i propanie wraz ze wzrostem dojrzałości substancji organicznej, z której gaz został wygenerowany, ulega zmianie i przyjmuje wartości coraz wyższe (bliższe zeru). W przypadku pierwotnego krakingu kerogenu typu pierwszego lub drugiego dla metanu wartość $\delta^{13} \mathrm{C}$ wynosząca $-50 \%$ oznacza początek okna ropnego, a wartość $\delta^{13} \mathrm{C}$ równa $-40 \%$ to koniec okna ropnego [11, 12]. Skład izotopowy węgla w metanie w większości próbek z formacji Barnett odpowiada oknu ropnemu, a w większości próbek z formacji Fayetteville - oknu gazowemu. Wartości składu izotopowego węgla w metanie wraz ze współczynnikiem wilgotności zostały przedstawione na wykresie Bernarda (rysunek 1) [1]. Większość analizowanych próbek gazów znaj-

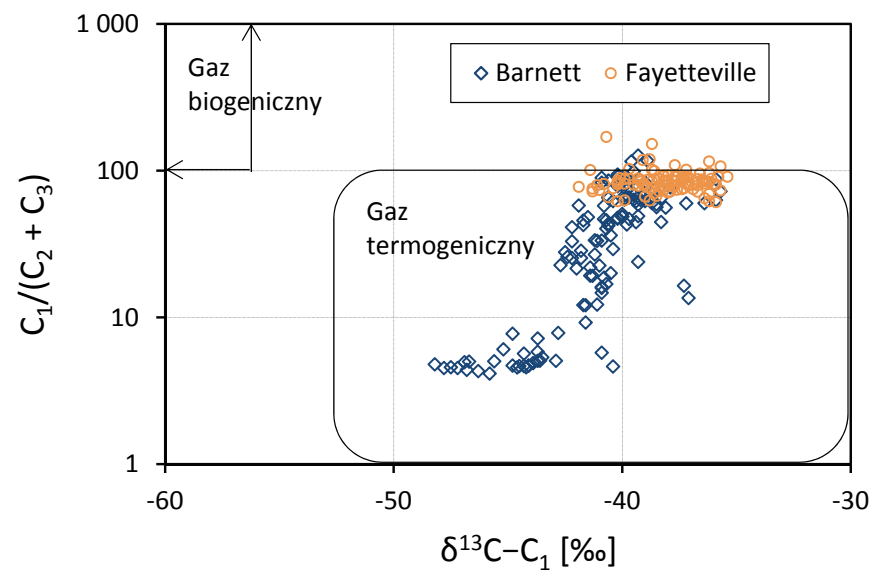

Rys. 1. Wykres Bernarda dla gazów z formacji Barnett i Fayetteville (zmodyfikowane za [1])

duje się w polu gazów termogenicznych. W celu precyzyjnego określenia rodzaju gazu naniesiono na wykres (według [5]) wartości $\delta^{13} \mathrm{C}$ i $\delta \mathrm{D}$ metanu (rysunek 2 ). Większość próbek gazów z formacji Barnett należy do pola gazów związanych z ropą naftową, a z formacji Fayetteville - do pola gazów niezwiązanych. Pozostałe próbki znajdują się w polu gazów mieszanych i w polu gazów związanych z kondensatem.

Skład izotopowy zarówno metanu $\left(\delta^{13} \mathrm{C}-\mathrm{C}_{1}\right)$, jak i etanu $\left(\delta^{13} \mathrm{C}-\mathrm{C}_{2}\right)$ i propanu $\left(\delta^{13} \mathrm{C}-\mathrm{C}_{3}\right)$ odzwierciedla dojrzałość sub-

Tablica 1. Wartości minimalne, maksymalne, mediany i średnie arytmetyczne składu izotopowego i wskaźników wyliczonych na podstawie składu chemicznego gazów z formacji Barnett

\begin{tabular}{|l|c|c|c|c|c|c|c|c|}
\cline { 2 - 9 } \multicolumn{1}{c|}{} & $\mathrm{C}_{1} /\left(\mathrm{C}_{2}+\mathrm{C}_{3}\right)$ & $\mathrm{C}_{2} / \mathrm{C}_{3}$ & $\mathrm{i}-\mathrm{C}_{4} / \mathrm{n}-\mathrm{C}_{4}$ & $\mathrm{i}-\mathrm{C}_{5} / \mathrm{n}-\mathrm{C}_{5}$ & $\delta^{13} \mathrm{C}-\mathrm{C}_{1}$ & $\delta^{13} \mathrm{C}-\mathrm{C}_{2}$ & $\delta^{13} \mathrm{C}-\mathrm{C}_{3}$ & $\delta \mathrm{D}-\mathrm{C}_{1}$ \\
\hline Wartość minimalna & 4,15 & 2,33 & 0,21 & 0,00 & $-48,20$ & $-41,70$ & $-36,80$ & $-188,00$ \\
\hline Wartość maksymalna & 126,78 & 40,50 & 2,00 & 3,02 & $-35,70$ & $-29,10$ & $-20,60$ & $-124,00$ \\
\hline Mediana & 42,61 & 18,00 & 0,71 & 1,11 & $-40,70$ & $-35,70$ & $-29,10$ & $-141,00$ \\
\hline Średnia arytmetyczna & 41,54 & 16,78 & 0,89 & 1,37 & $-41,14$ & $-35,54$ & $-28,86$ & $-142,88$ \\
\hline
\end{tabular}

Tablica 2. Wartości minimalne, maksymalne, mediany i średnie arytmetyczne składu izotopowego i wskaźników wyliczonych na podstawie składu chemicznego gazów z formacji Fayetteville

\begin{tabular}{|l|c|c|c|c|c|c|c|c|}
\cline { 2 - 9 } \multicolumn{1}{c|}{} & $\mathrm{C}_{1} /\left(\mathrm{C}_{2}+\mathrm{C}_{3}\right)$ & $\mathrm{C}_{2} / \mathrm{C}_{3}$ & $\mathrm{i}-\mathrm{C}_{4} / \mathrm{n}-\mathrm{C}_{4}$ & $\mathrm{i}-\mathrm{C}_{5} / \mathrm{n}-\mathrm{C}_{5}$ & $\delta^{13} \mathrm{C}-\mathrm{C}_{1}$ & $\delta^{13} \mathrm{C}-\mathrm{C}_{2}$ & $\delta^{13} \mathrm{C}-\mathrm{C}_{3}$ & $\delta \mathrm{D}-\mathrm{C}_{1}$ \\
\hline Wartość minimalna & 60,94 & 27,00 & 0,07 & 0,13 & $-41,90$ & $-46,10$ & $-45,20$ & $-153,00$ \\
\hline Wartość maksymalna & 169,98 & 122,00 & 0,85 & 6,33 & $-35,40$ & $-37,90$ & $-33,60$ & $-123,00$ \\
\hline Mediana & 83,33 & 56,75 & 0,23 & 0,89 & $-38,05$ & $-43,10$ & $-41,65$ & $-133,00$ \\
\hline Średnia arytmetyczna & 84,96 & 60,36 & 0,26 & 1,16 & $-38,18$ & $-42,97$ & $-41,38$ & $-132,81$ \\
\hline
\end{tabular}




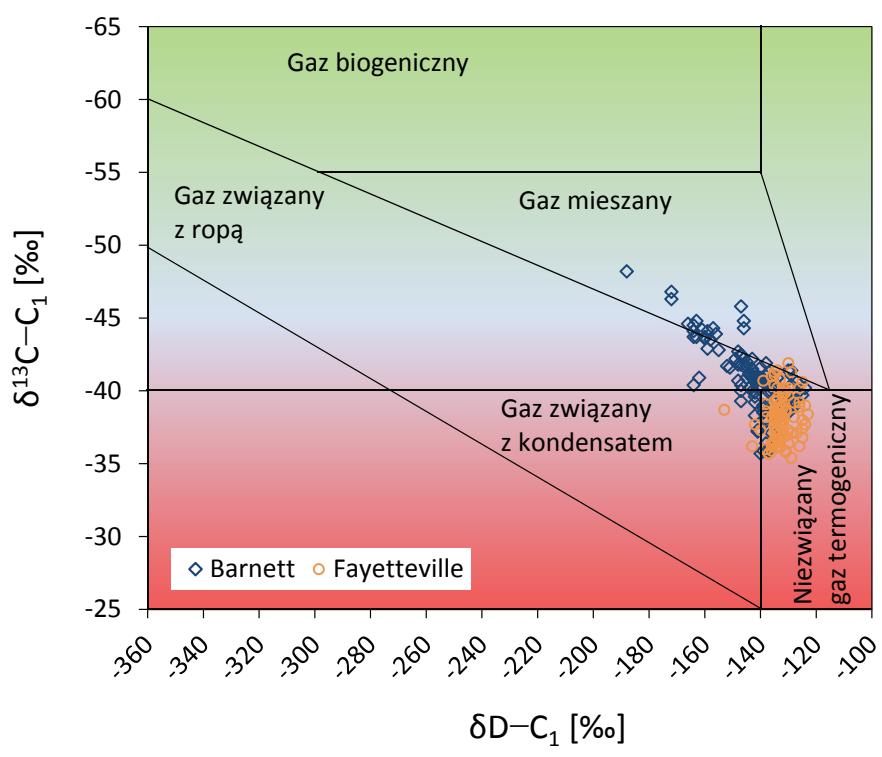

Rys. 2. Wykres określający rodzaj gazu w zależności od składu izotopowego węgla i wodoru w metanie (zmodyfikowane za [8])

stancji organicznej (refleksyjność witrynitu - $V R_{o}$ ) i rodzaj gazu. Zależności te są wyrażone wzorami:

$$
\begin{aligned}
& \delta^{13} \mathrm{C}-\mathrm{C}_{1}(\% 0)=15,4 \log _{(10)} \% V R_{o}-41,3 \\
& \delta^{13} \mathrm{C}-\mathrm{C}_{2}(\% 0)=22,6 \log _{(10)} \% V R_{o}-32,2 \\
& \delta^{13} \mathrm{C}-\mathrm{C}_{3}(\% 0)=20,9 \log _{(10)} \% V R_{o}-29,7
\end{aligned}
$$

Wzory (1), (2) i (3) pozwalają szacować dojrzałość na podstawie składu izotopowego dla gazu termogenicznego pochodzącego z pierwotnego krakingu kerogenu typu I i II [11]. Dane z analiz składu izotopowego węgla w metanie, etanie i propanie zostały zestawione na rysunkach 3 i 4 . Na wykres naniesiono dodatkowo krzywe będące teoretycznymi wartościami składu izotopowego otrzymanymi z powyższych wzorów. Widać, że skład izotopowy próbek mocno odbiega od teoretycznych wartości, podobnie jak w przypadku gazów z polskich formacji łupkowych [5].

Wszystkie próbki gazów z formacji Fayetteville (dojrzałość substancji źródłowej od około $2 \%$ do $3 \% V R_{o}$ ) wykazują efekt roll-over, a próbki z formacji Barnett (dojrzałość substancji źródłowej od około $1 \%$ do $2 \% V R_{o}$ ) są mocno zróżnicowane. Wzory Whiticara nie mogą być stosowane dla próbek ze stwierdzoną inwersją składu izotopowego, a ich wykorzystanie w przypadku pozostałych gazów z formacji łupkowych może być obarczone dużym błędem. Dodatkowo dla gazów z formacji łupkowych zmiana składu izotopowego węgla w metanie i etanie wraz ze wzrostem po- ziomu dojrzałości substancji organicznej, na którym następuje generacja gazu, wydaje się nie być zależnością liniową (jak w przypadku gazów konwencjonalnych), a wykładniczą.

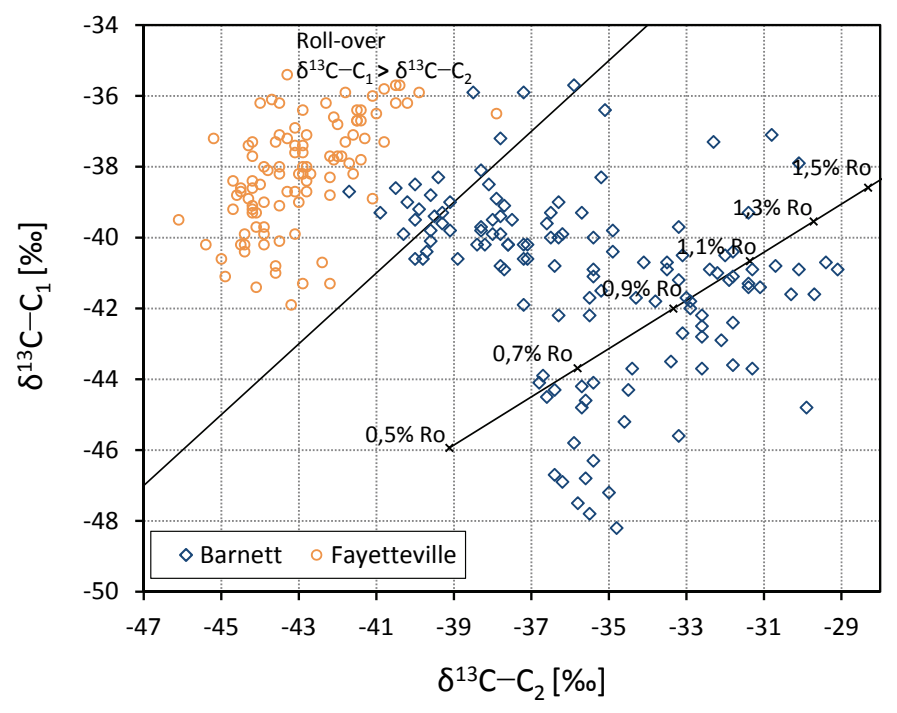

Rys. 3. Wykres zestawiający $\delta^{13} \mathrm{C}-\mathrm{C}_{2} \mathrm{z} \delta^{13} \mathrm{C}-\mathrm{C}_{1}$ dla próbek gazów $\mathrm{z}$ formacji Barnett i Fayetteville (zmodyfikowane za [11])

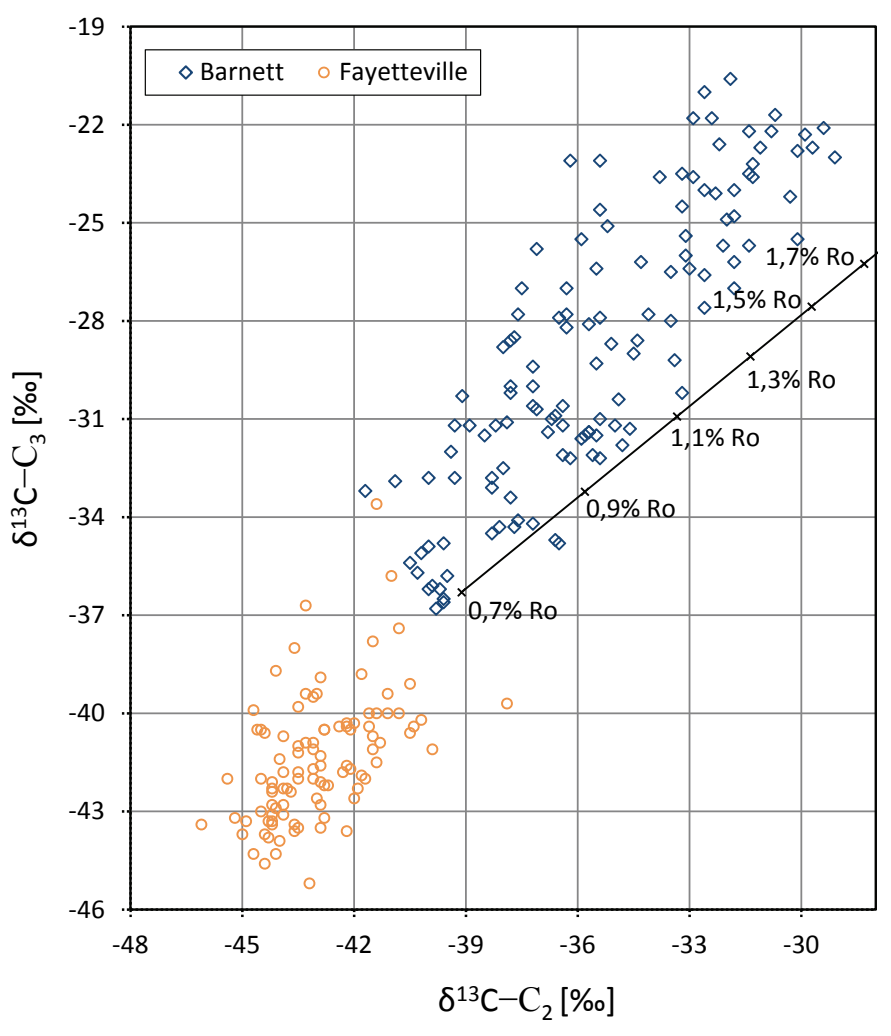

Rys. 4. Wykres zestawiający $\delta^{13} \mathrm{C}-\mathrm{C}_{2} \mathrm{z} \delta^{13} \mathrm{C}-\mathrm{C}_{3}$ dla próbek gazów z formacji Barnett i Fayetteville (zmodyfikowane za [11])

\section{Wtórny kraking}

Na wtórny kraking mogą wskazywać dwa parametry gazu: $\mathrm{C}_{2} / \mathrm{C}_{3}$ oraz $\delta^{13} \mathrm{C}-\mathrm{C}_{2}-\delta^{13} \mathrm{C}-\mathrm{C}_{3}$. Stosunek zawartości etanu i propanu rośnie wraz ze wzrostem dojrzałości i osiąga najwyższe wartości przy występującym wtórnym krakingu cięż- 
szych składników gazu (rysunek 5). Różnica składu izotopowego etanu i propanu przyjmująca wartości mniejsze od około $-4 \%$ oznacza wtórny kraking ropy naftowej lub cięższych składników gazu [2, 4, 6]. Mniej dojrzałe próbki z formacji Barnett trzymają się tego trendu; dopiero przy wartości $\mathrm{C}_{2} / \mathrm{C}_{3}$ około 20 następuje zmiana i wartości $\delta^{13} \mathrm{C}-\mathrm{C}_{2}-\delta^{13} \mathrm{C}-\mathrm{C}_{3}$ zaczynają rosnąć, zamiast maleć.

Rys. 5. Wykres zestawiający $\mathrm{C}_{2} / \mathrm{C}_{3} \mathrm{z} \delta^{13} \mathrm{C}-\mathrm{C}_{2}-\delta^{13} \mathrm{C}-\mathrm{C}_{3}$ dla próbek gazów $\mathrm{z}$ formacji Barnett i Fayetteville

(zmodyfikowane za [6])

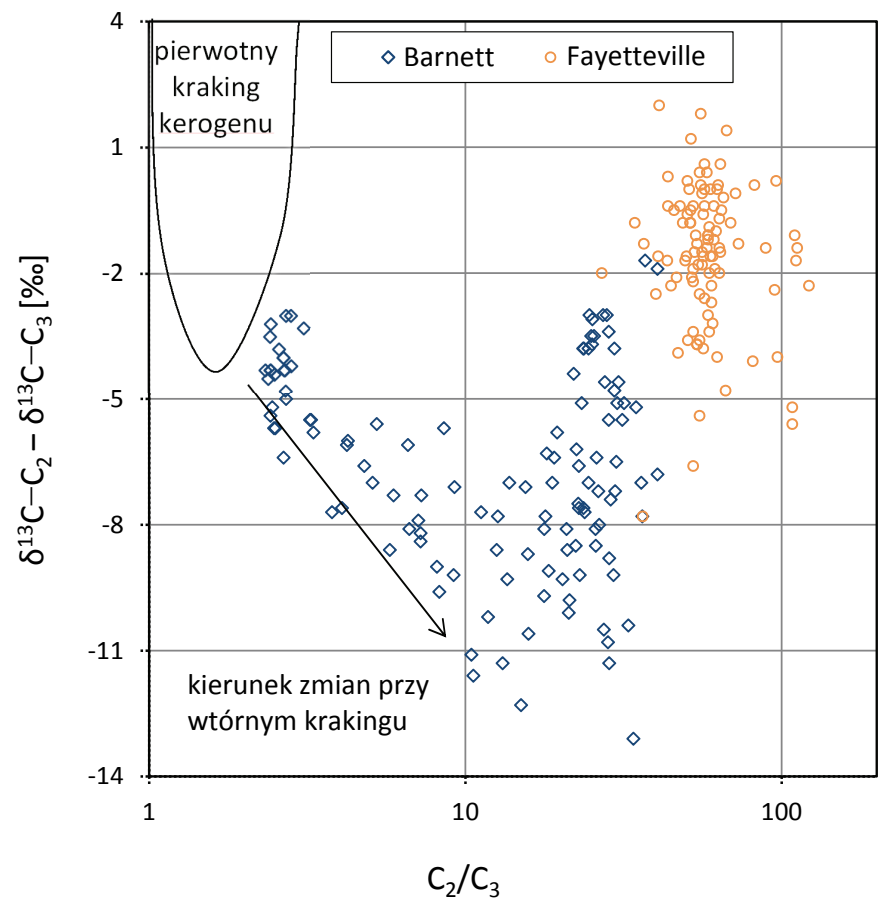

\section{Izomeryzacja butanu i pentanu}

Wskaźniki izomeryzacji butanu $\left(\mathrm{i}-\mathrm{C}_{4} / \mathrm{n}-\mathrm{C}_{4}\right)$ oraz penta$\mathrm{nu}\left(\mathrm{i}-\mathrm{C}_{5} / \mathrm{n} \mathrm{C}_{5}\right)$ wzrastają wraz z dojrzałością substancji organicznej generującej gaz aż do wartości odpowiednio około 1 oraz 2. Dla gazów z formacji Barnett obydwa te wskaźniki rosną aż do uzyskania przez współczynnik $\mathrm{C}_{1} /\left(\mathrm{C}_{2}+\mathrm{C}_{3}\right)$ wartości około 20, a następnie obydwa wskaźniki izome-

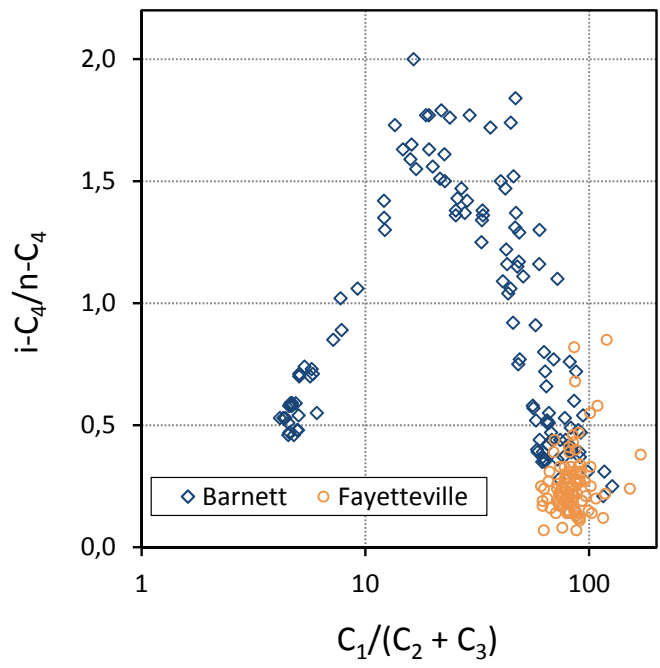

Rys. 6. Wykres zestawiający $\mathrm{C}_{1} /\left(\mathrm{C}_{2}+\mathrm{C}_{3}\right)$ z i-C $\mathrm{C}_{4} / \mathrm{n}-\mathrm{C}_{4}$ dla próbek gazów $\mathrm{z}$ formacji Barnett i Fayetteville ryzacji zaczynają maleć (rysunek 6 i 7). Dodatkowo mogą osiągać, niespotykane dla gazów generowanych z klasycznych skał macierzystych, wysokie wartości - odpowiednio około 2 oraz 3 [3]. Wraz ze wzrostem dojrzałości następuje również inwersja składu chemicznego butanów i pentanów, która w przypadku gazów konwencjonalnych nie występuje.

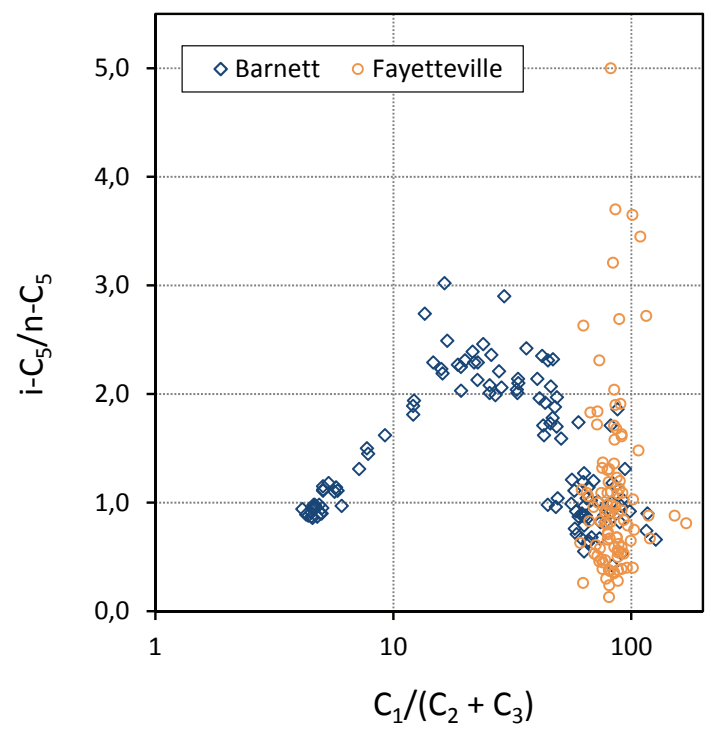

Rys. 7. Wykres zestawiający $\mathrm{C}_{1} /\left(\mathrm{C}_{2}+\mathrm{C}_{3}\right)$ z i- $\mathrm{C}_{5} / \mathrm{n}-\mathrm{C}_{5}$ dla próbek gazów $\mathrm{z}$ formacji Barnett i Fayetteville

\section{Podsumowanie}

1. Wszystkie próbki gazów z formacji Fayetteville (dojrzałość substancji źródłowej od około $2 \%$ do 3\% VR ) wy- kazują efekt roll-over, a próbki z formacji Barnett (dojrzałość substancji źródłowej od około $1 \%$ do $2 \% V R_{o}$ ) 
są mocno zróżnicowane. Wzory Whiticara nie mogą być stosowane do próbek ze stwierdzoną inwersją składu izotopowego, a w przypadku pozostałych gazów z formacji łupkowych ich wykorzystanie może być obarczone dużym błędem.

2. Parametry $\delta^{13} \mathrm{C}-\mathrm{C}_{2}-\delta^{13} \mathrm{C}-\mathrm{C}_{3} \mathrm{i}_{2} / \mathrm{C}_{3}$ mogą wskazywać na występowanie wtórnego krakingu (trend zmian to spadek wartości $\delta^{13} \mathrm{C}-\mathrm{C}_{2}-\delta^{13} \mathrm{C}-\mathrm{C}_{3} \mathrm{i}$ wzrost wartości $\mathrm{C}_{2} / \mathrm{C}_{3}$ wraz ze wzrostem dojrzałości). W przypadku próbek z Barnett i Fayetteville widać zmianę trendu przy $\mathrm{C}_{2} / \mathrm{C}_{3}$ wynoszącym około 20, która dla gazów konwencjonalnych nie występuje.

3. W przypadku gazów z formacji Barnett oraz Fayetteville wraz ze wzrostem dojrzałości termicznej źródłowej substancji organicznej następuje inwersja składu chemicznego butanów i pentanów.

Prosimy cytować jako: Nafta-Gaz 2016, nr 10, s. 785-789, DOI: 10.18668/NG.2016.10.02

Artykuł nadesłano do Redakcji 18.03.2016 r. Zatwierdzono do druku 29.07.2016 r.

Artykuł powstał na podstawie pracy statutowej pt. Wptyw wtórnego krakingu w formacjach łupkowych na występowanie inwersji sktadu izotopowego $w$ metanie, etanie i propanie (tzw. efekt roll-over) - praca INiG - PIB na zlecenie MNiSW; nr zlecenia 75/SG/2015, numer archiwalny DK-4100-75/15.

\section{Literatura}

[1] Bernard B. B., Brooks J. M., Sackett W. M.: Light hydrocarbons in recent Texas continental shelf and slope sediments. Journal of Geophysical Research 1978, vol. 83, s. 4053-4061.

[2] Ellis L., Brown A., Schoell M., Uchytil S.: Mud gas isotope logging (MGIL) assists in oil and gas drilling operations. Oil \& Gas Journal 2003, vol. 101, no. 21, s. 32-41.

[3] Hao F., Zou H.: Cause of shale gas geochemical anomalies and mechanisms for gas enrichment and depletion in highmaturity shales. Marine and Petroleum Geology 2013, vol. 44, s. $1-12$.

[4] Hill R. J., Zhang E., Katz B. J., Tang Y.: Modeling of gas generation from the Barnett Shale, Fort Worth Basin, Texas. AAPG Bulletin 2007, vol. 91, no. 4, s. 501-521.

[5] Janiga M., Kania M., Matyasik I.: The isotopic composition of gaseous hydrocarbons - tool for polish shale gas system evaluation. Nafta-Gaz 2015, nr 6, s. 370-375.

[6] Lorant F., Prinzhofer A., Behar F., Huc A. Y.: Carbon isotopic and molecular constraints on the formation and the expulsion of thermogenic hydrocarbon gases. Chemical Geology 1998, vol. 147 , no. 3-4, s. 249-264.

[7] Matyasik I., Słoczyński T.: Niekonwencjonalne złoża gazushale gas. Nafta-Gaz 2010, nr 3, s. 167-177.

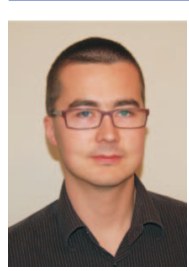

Mgr inż. Marek JANIGA

Asystent w Zakładzie Geologii i Geochemii. Instytut Nafty i Gazu - Państwowy Instytut Badawczy ul. Lubicz 25 A

31-503 Kraków

E-mail: marek.janiga@inig.pl
[8] Peters K. E., Walters C. C., Moldowan J. M.: The Biomarker Guide. Volume 1. Biomarkers and Isotopes in the Environment and Human History. Cambridge University Press, 2005.

[9] Pollastro R. M., Jarvie D. M., Hill R. J., Adams C. W.: Geologic framework of the Mississippian Barnett Shale, BarnettPaleozoic total petroleum system, Bend Arch-Fort Worth Basin, Texas. AAPG Bulletin 2007, vol. 91, s. 405-436.

[10] Ratchford M. E., Bridges L. C., Jordan D., Dow W. G., Colbert A., Jarvie D. M.: Organic Geochemistry and Thermal Maturation Analysis within the Fayetteville Shale Study Area. Eastern Arkoma Basin and Mississippi Embayment regions, Arkansas. Arkansas Geological Commission Information Circular 2006, vol. 37.

[11] Whiticar M. J.: Correlation of natural gases with their sources. AAPG Memoir 1994, vol. 60, s. s. 261-283.

[12] Whiticar M. J., Faber E.: Methane oxidation in sediment and water column environments - isotope evidence. Organic Geochemistry 1986, vol. 10, nr 4-6, s. 759-768.

[13] Zumberge J., Ferworn K., Brown S.: Isotopic reversal rollover in shale gases produced from the Mississippian Barnett and Fayetteville formations. Marine and Petroleum Geology 2012, vol. 31, nr 1, s. 43-52.

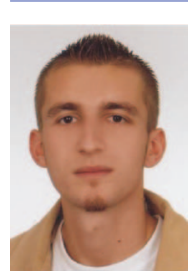

Mgr inż. Wojciech BIELEŃ

Starszy specjalista badawczo-techniczny w Zakładzie Geologii i Geochemii.

Instytut Nafty i Gazu - Państwowy Instytut Badawczy ul. Lubicz 25 A

31-503 Kraków

E-mail: wojciech.bielen@inig.pl 